\title{
Production Planning and Control of a Master Churn Mixer for the Manufacture of Margarine using Fuzzy Logic at an Oil Company in Zimbabwe
}

\author{
Wilson R. Nyemba ${ }^{1}$, Tawanda Mushiri ${ }^{1}$, Kumbi Mugwindiri ${ }^{2}$, Roy Mushonga ${ }^{2}$, and Charles \\ Mbohwa $^{3}$ \\ ${ }^{1}$ Department of Mechanical Engineering Science, Faculty of Engineering \& the Built Environment, \\ University of Johannesburg, Auckland Park 2006, Johannesburg, South Africa \\ nyemba@yahoo.com, tawanda.mushiri@gmail.com \\ ${ }^{2}$ Department of Mechanical Engineering, Faculty of Engineering, University of Zimbabbwe, P O Box \\ MP 167, Mount Pleasant, Harare, Zimbabwe \\ kmugwindiri@eng.uz.ac.zw, nyasharoy@gmail.com \\ ${ }^{3}$ Professor of Sustainability Engineering, Department of Quality and Operations Management \& Vice \\ Dean for Research and Innovation, Faculty of Engineering and the Built Environment, University of \\ Johannesburg, Auckland Park 2006, Johannesburg, South Africa,cmbohwa@uj.ac.za
}

\begin{abstract}
Process and chemical companies have to continually monitor and control their mixing equipment to ensure that production matches requirements and meets recommended standards especially in food processing. The oil company in this research faced challenges in meeting required specifications in some of their batches, prompting the need to look at more efficient ways to control and monitor the master churn mixer. This paper looks at how intelligent fuzzy logic was used to automate the production planning and control of the master churn mixer of the margarine plant. MATLAB 7.12 was used in developing the control algorithm that enabled all the inputs to be monitored closely before they entered the master churn, while maintaining vegetable oil at $80 \%$, water at $20 \%$ and operating temperature at $38^{\circ} \mathrm{C}$. This was enabled by sensors and programmable logic controllers which monitored all parameters using fuzzy logic to produce margarine of acceptable quality and standards.
\end{abstract}

Keywords: fuzzy logic, master churn mixer, production planning and control.

\section{Introduction}

The research was carried out in 2013 at an oil company that specializes in food production, one of the main lines being the production of various types of margarine products. This was a typical process industry involved in continuous processing through standardizing non-discrete products in large volumes using a continuous process. Such manufacturing activity is considered to be "in control" when the resulting performance is within the objectives of the planned performance $[1,2]$. The case study company faced a number of challenges over the last few years where customer demands were not met due to delays in the production process largely because of failure to meet the expected quality standards thereby forcing reruns in the plant. This was also partly attributed to shortfalls in production planning and control. However, with careful planning, control and execution, the company had the 
potential and capacity to optimally run plant operations, thus utilizing the manufacturing facilities fully and effectively. The major challenge that the company faced was in job scheduling,to determine when to run a process and when the set task should be completed. This adversely affected the flexibility in production operations, full utilization of resources, and the coordination between these. Thus, the critical factor for the company to meet or achieve its objectiveswas downtime. Assessing these variables closely will not only enable the company to analyze and track their manufacturing processes but will also allow them to evaluate success in relation to set goals and objectives [3].

Inadequately trained and skilled operators also contributed to delays in meeting customer demands because of failure to operate some of the equipment optimally and thereby failing to closely monitor and control production. In general, chemical processing especially in food production, has to follow stringent quality control measures to ensure that the food produced is not harmful to consumers. The focus of the research was on the master churn mixer which is used in the production of various types of margarine products where it was evident that some of the batches were failing to meet specified quality standards. In view of the possible contribution by lack of skills to control the processing equipment, the aim of the research was to design an automated and intelligent system to monitor and control the master churn production and mixing processes with the objective of manufacturing margarine with a blend of $80 \%$ vegetable oil or animal fat and $20 \%$ water with added salt, flavorings, colour, preservatives and emulsifiers, while maintaining temperature at $38^{\circ} \mathrm{C}$ in the production setup.

\section{Background and literature review}

Production processes involve the conversion of raw materials into semi-finished or finished products and in the process adding value to the final products [4]. Generally, planning, which can be strategic, tactical or operational, involves documenting the flow of actions to achieve an intended goal. In this research, strategic planning was used as it brought future projections to the organization with minimal or no problems during the production process. Control on the other hand requires practitioners to exercise authority or have influence over something [5]. Production Planning and Control (PPC), is thus an acquisition and allocation of limited resources to production activities so as to satisfy customer demands over a specified period [6].

Processing industries are characterized by different departments through which raw materials are processed in stages until the final product. For a successful business, the various departments work closely together in a holistic manner, to ensure continuity and the achievement of quality and standards in a company's products. Production planning uses the total quality management principle in that all stakeholders are brought together in order to assess future market demands and generate changes in the business and in so doing, the interconnectedness of the departments and various units become intertwined in a systems thinking manner such that one cannot function without the full operations of the others. 


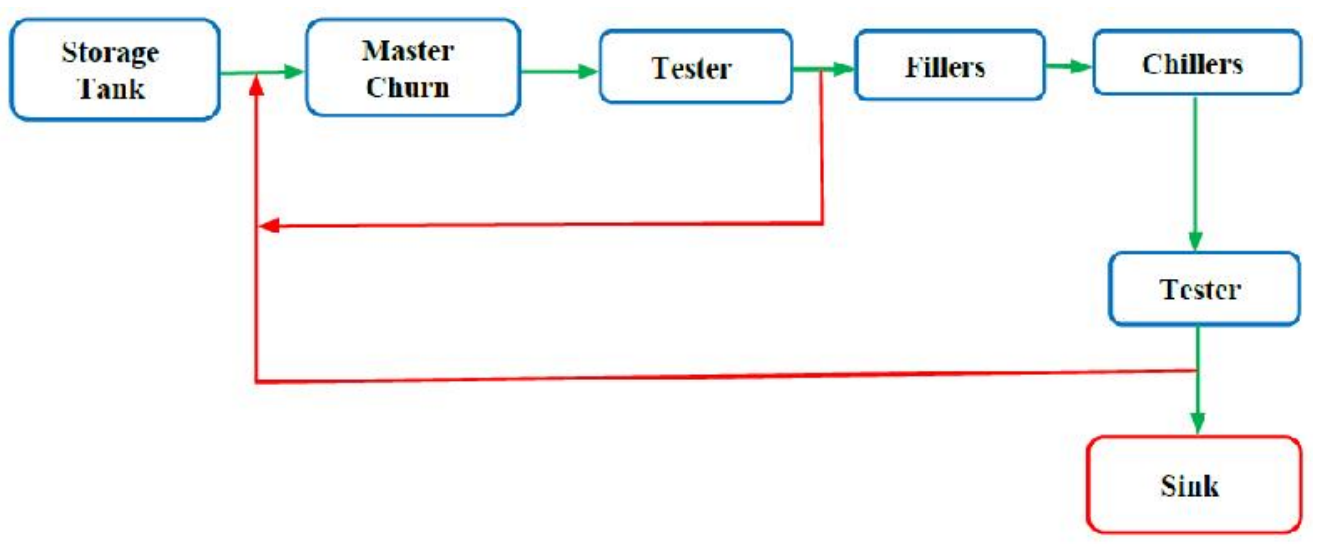

Fig. 1.Process flow chart for margarine production

Fig. 1 summarizes the process flows for the manufacture of the various types of margarine products at the company. As a trial run and to ensure that the intended intelligent controller achieved the purpose of monitoring the production process, a pilot section on the master churn mixer was selected. Due to the fact that the master churn mixer is one of the main centers of activity in margarine production, there was need to analyze the activities occurring during processing. The main purpose of the master churn is to process and mix different types of ingredients used to produce margarine. During the process there are also some losses incurred, such as energy losses.

In general, operators of the master churn mixer are involved in a number of tasks in the various stages of the mixing process at this work center [7]. Apart from observing the production and monitoring the equipment to ensure safe and efficient operations, they are also required to record operational or production data on specified forms as well as documenting processes and noting any anomalies in production. The feeding of specified and correct quantities of raw materials and ingredients into the mixer and transfer of the materials, supplies or products between work areas, is accomplished through the use of moving equipment or hand tools. The operators also carry out inspection of materials, ingredients or products to ensure conformity with established standards. The master churn mixer is supposed to be kept in a clean and safe environment hence the need to continually clear the area surrounding it as well as regularly opening valves to drain slurry.

Margarine is a blend of $80 \%$ vegetable oil or animal fat, and $20 \%$ water with added salt, flavorings, color, and preservatives. In many countries these proportions are controlled by legislation and must be maintained at those levels and a processing temperature of $38^{\circ} \mathrm{C}$ for good quality margarine [8]. The cream is placed in a large, mechanical churn usually made of aluminum, some of which can produce $680-2,300 \mathrm{~kg}$ of margarine at a time. When the churn is in operation it mixes the cream in the same manner as a tumble dryer, while an operator monitors the process through a protected glass window on the master churn. After about 45 minutes, small granules of margarine begin to form, and the margarine and milk are separated. Salt is then added, and the mixture is churned further. When this process is completed, a stainless steel container is placed adjacent to the opening of the mechanical churn, which is then opened and the margarine flows into the container. It is then wrapped into $30 \mathrm{~kg}$ cartons and transported to the distributor where it is packaged for consumer and food-service industry use. 
Quality control is an obvious concern at modern food-processing facilities. Unclean equipment and inconsistent operations can lead to mass bacterial contamination. The U.S. government, under the auspices of the Department of Agriculture, maintains specific industrial hygiene codes for modern creameries and margarine manufacturing plants [9]. Inspections and fines for poorly maintained equipment or unclean conditions help in keeping companies in compliance. Margarine is graded by the United States Department of Agriculture inspectors at the creamery who inspect, test, taste and assign scores, a maximum of 45 for flavor, 25 for body and texture, 15 for color, 10 for salt content, and 5 for packaging [9]. Thus, a perfect batch of margarine can receive a score of 100 but usually the highest number assigned to a package is 93 classified and labeled Grade AA while a batch that receives a score below 90 is considered inferior. Guidelines for margarine production dictate that margarine contains $80 \%$ fat [10]. The oils used in the production can be derived from a variety of animal fat or vegetable oil but they must all be fit for human consumption. Its aqueous content may be milk, water, or a soy-based protein fluid. It must be pasteurized and contain at least 15,000 units of vitamin A. It may also contain a salt substitute, sweeteners, fatty emulsifiers, preservatives, vitamin D, and coloring agents [8].

Fuzzy logic is now widely used in machine control. For many, the use of this technique is still quite confusing, especially from the terminology 'fuzzy' which may mean 'unclear', 'half-baked' or 'bogus'. However the use of this term does not refer to these or weakness in the methodology used but rather to the logic involved, which deals with fuzzy concepts, i.e. those that cannot be expressed as 'True' or 'False' but rather 'Partially True' or 'Partially False' [11]. Genetic Algorithms (GAs) and Neural Networks (NNs) can perform just as well as fuzzy logic, in many cases there are a lot of mathematical similarities. However fuzzy logic has the advantage that, interpreting and using them in designing a controller for the master churn would be simpler than employing GAs or NNs [12]. This makes it easier to mechanize tasks that are already successfully performed by humans [13].A logic based on the two values TRUE or FALSE is sometimes inadequate when describing human reasoning. Fuzzy logic uses the whole interval between 0 (FALSE) and 1(TRUE) to describe human reasoning [11]. As a result, fuzzy logic has been applied in rule based automatic controllers [14]. A fuzzy logic controller consists of 4 main components, a fuzzifier, inference engine, knowledge base and a defuzzifier as shown in Fig.2 [15].

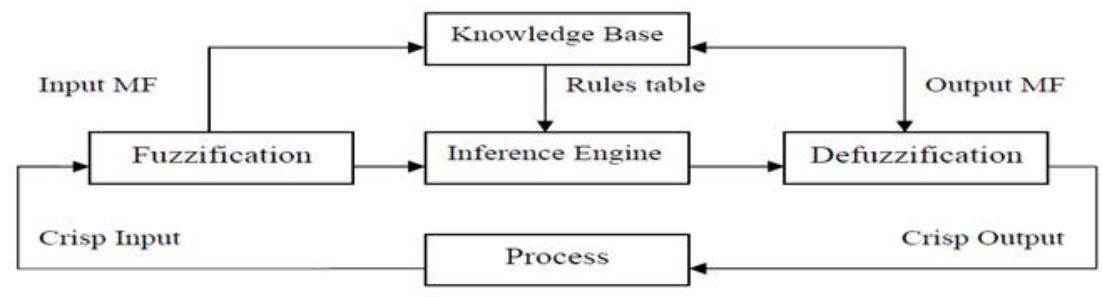

Fig.2. Fuzzy logic controller

Fuzzification combines actual values (e.g., barometric pressure) with stored membershipfunction data to produce fuzzy input values. Rule evaluation, or fuzzy inferencing is a way of producing numeric responses from linguistic rules based on system input values and finally, defuzzification combines all its outputs and obtains a representative number. To see if this number solves the original problem and gives one an accurate answer in all cases, it's 
necessary to come up with a performance measure (theoretically, an ideal correct response). One can then run the engine in a variety of contexts. If the number doesn't turn out to be a good solution, the system parameters can be tuned to reach a satisfactory conclusion.Fuzzy rules are used in fuzzy control in order to define the map from the fuzzy input signals (error, measured or command signals) of the fuzzy controller to its fuzzy output signals or control signals. Fuzzy logic has fuzzy Single Input, Single Output (SISO) AND OR rules [16].A connection between cause and effect, or a condition and a consequence is made by reasoning which can be expressed by a logical inference or by the evaluation of inputs in order to draw a conclusion, usually following rules of inference which have the form: IF causel $=A$ and cause $2=B$, THEN effect $=C$, where $\mathrm{A}, \mathrm{B}$ and $\mathrm{C}$ are linguistic variables. For example, IF "room temperature" is Medium THEN "set fan speed to Fast" where Medium is a function defining degrees of room temperature while Fast is a function defining degrees of speed. The intelligence lies in associating those two terms by means of an inference expressed in heuristic IF...THEN terms [17].

Having established the operations of the master churn mixer, specifications and standards required for good quality margarine, this research set out to answer questions on what was causing the failure by the oil company to meet customer demands timely and how this challenge can be solved to ensure smooth and uninterrupted processing and mixing in the master churn and how the designedintelligent fuzzy controller fully accomplishes the task to monitor and control the operations of the master churn mixer and how that impacted on production.

\section{Research methodology}

Condition Based Maintenance (CBM) is a necessary strategy in process industries to monitor the actual condition of equipment in order to decide what maintenance needs to be carried out from time to time [18]. CBM dictates that maintenance should only be performed when certain indicators show signs of decreasing performance or upcoming failure. Due to its nature and simplicity, the use of fuzzy logic in decision making and control, complements other tools in CBM to map inputs to outputs through fuzzification, rule evaluation, and defuzzification. In this research, data (temperature, water and vegetable oil proportions) was obtained and measured from the master churn mixer for a period of six months. This was prompted by challenges on realising that temperature, vegetable oil and water ratios were not consistent resulting in products not conforming to the required standards, hence the need to control and monitor these parameters. The desired range was programmed as acceptable and any values outside this were rejected. Following the various stages of fuzzy logic as summarized in Fig. 2, simulations of the process was carried out using MATLAB 7.12 from fuzzification to defuzzification. Fig. 3(a) shows a snapshot of the inputs; vegetable oil, water and temperature as key parameters that need to be controlled in the preparation of margarine. A Mamdani fuzzy inference approach was used which required defuzzification and the IFTHEN-ELSE rule was defined by the fuzzy set to enable the creation of an intelligent and adaptive system [19]. The output fuzzy set of each rule was reshaped by a matching number, and defuzzification was required after aggregating all of these reshaped fuzzy sets [20]. The fuzzy logic toolbox in MATLAB was used to work hand in hand with sensors and Programmable Logic Controllers (PLCs) as feedback to monitor water, oil and temperature parameters to ensure that they remained within the desirable range. This range was derived 
from previous research and was used in the coding and defuzzification for the desired outcome [7]. By using MATLAB M-files or scripts, the user is prompted to enter inputs, thereby the program reads and makes choices as to whether statements or steps were executed. This enabled monitoring of the system, for instance if a certain limit or minimum level was reached, then the system will automatically determine what to execute, through the use of the IF-THEN-ELSE statement.
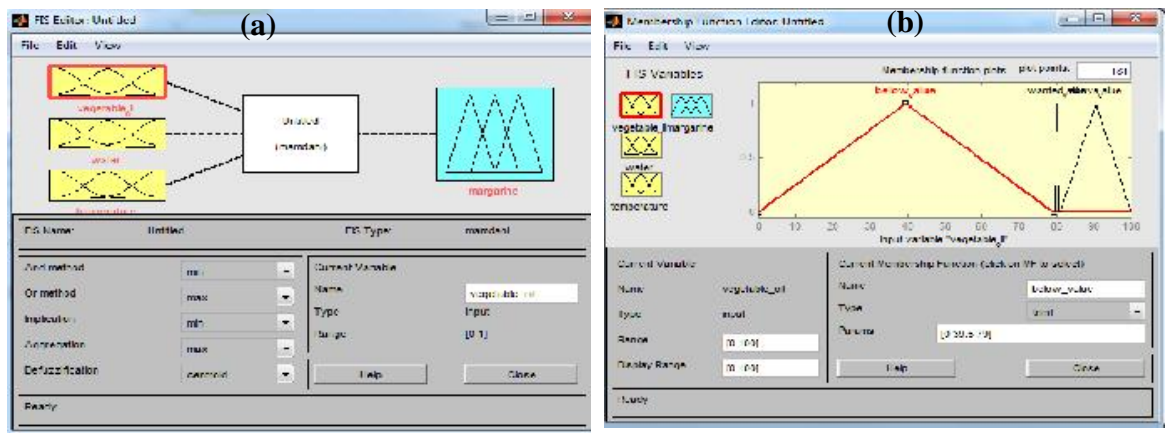

Fig. 3. (a) Fuzzy inputs and (b) Vegetable margarine membership function

Fig. 3(b) shows a snapshot where focus was concentrating on the required percentages and the undesirable ones. For the input variable of vegetable oil, anything below $80 \%$ was unacceptable and was rejected to prompt the machine to stop automatically. This was done by sensors which detected the required amount to proceed with the process or not. Similarly any values above $80 \%$ meant it was in excess and it was also rejected, thereby maintaining the exact desirable figure of $80 \%$. The variable input of water was also monitored as shown in Fig. 4 (a) and controlled and maintained at the desirable 20\%. High or low amounts of water are also undesirable in the manufacturing process. Fig. 4(b) shows the temperature membership function where desirable temperature was maintained at around $37 \%$ according to specifications, to avoid poor quality margarine. The display range was taken as between $0 \%$ and $40 \%$. The research was partly based on assumptions and working under good and bad conditions with limited inputs and their inadequacy compared to the throughput generated. These assumptions were based on key performance indicators of the production line and experience of working with the master churn mixer.
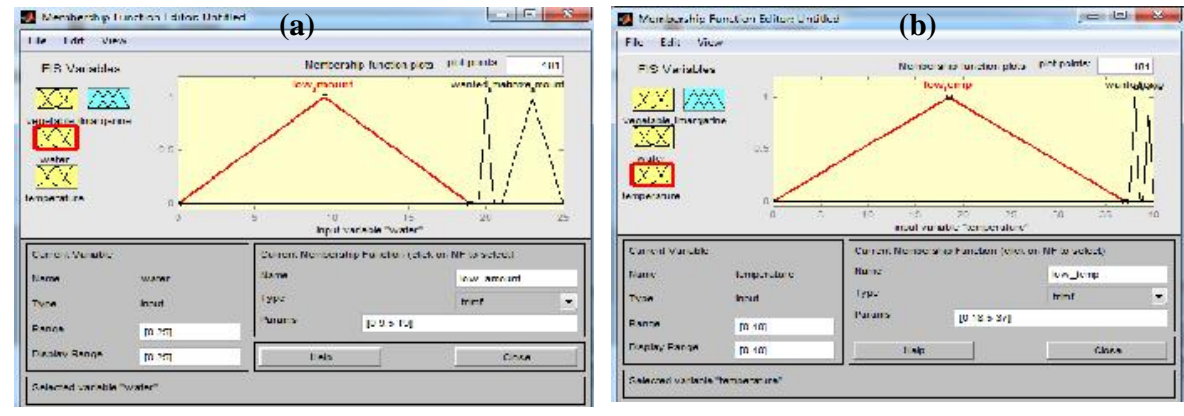
Fig. 4. (a) Water membership function and (b) Temperature membership function

\section{Results}

Fig. 5(a) shows the output stage, where only two conditions apply, either to run the process and mix the margarine or stop in the event that desirable values were not achieved. All inputs were controlled and monitored before processing began to ensure proper production planning and a reduction in waste in terms of inventory control. Five rules were generated as shown in Fig. 5(b) to ensure automation of the whole process.
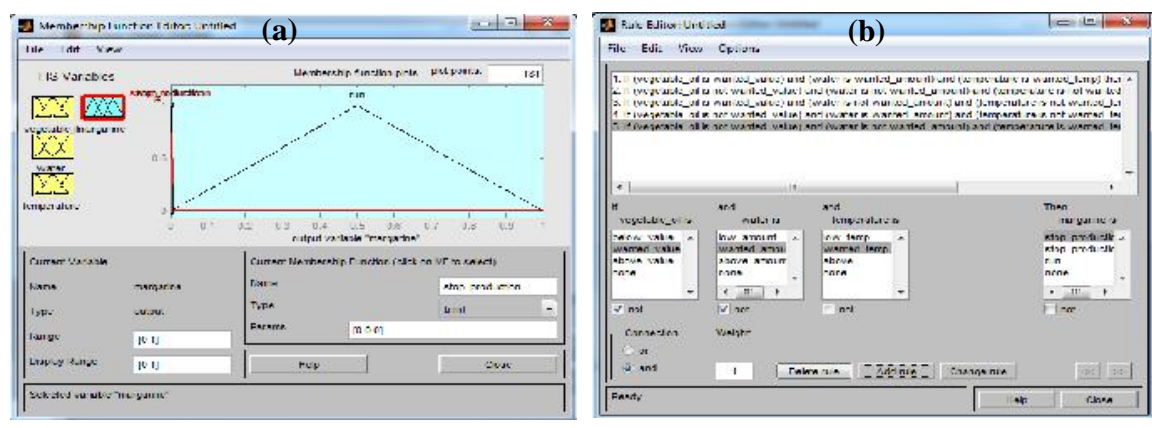

Fig. 5. (a) Margarine output control and(b) Rule editor for the margarine process

Fig. 6(a) shows a snapshot of the rule viewer summarizing the rules generated for the manufacturing variables with temperature maintained at $38^{\circ} \mathrm{C}$ while water and vegetable oil were controlled and maintained at $20 \%$ and $80 \%$ respectively to ensure smooth processing and good quality margarine output. This control algorithm and sensors also ensured that if the parameters were outside this range, the machine will stop even if an operator physically switches it on by mistake. This results in a fully automated master churn mixer that can run without the intervention of operators unless it is under maintenance in which case the operators will switch it on to continue after the maintenance but the system will first check that the desired values are maintained before running. Maintaining the temperature at the desirable $38^{\circ} \mathrm{C}$ ensured that the output did not have any losses as shown in the snapshot surface viewer for vegetable oil on Fig. 6(b), displaying perfect processing of the product. This eliminates the need for operators as well as maintaining and improving the quality of margarine, thereby ensuring unwarranted stoppages and delays in production.
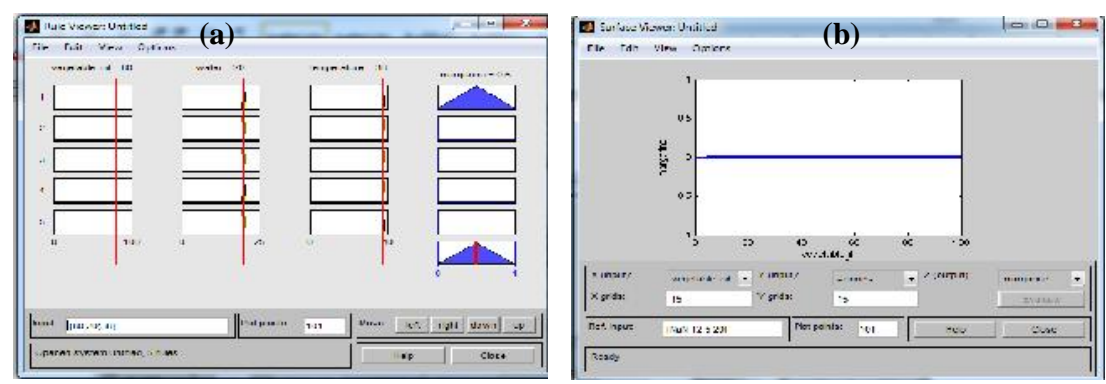
Fig. 6. (a) Rule viewer for all inputs and outputs and (b) Surface viewer for vegetable oil

\section{Discussion and recommendations}

The main objective of any business organization, be it in manufacturing, processing or service industry, is to make profit in order for the business to continue functioning. This is however dependent on the business's departments functioning to full capacity. For processing and manufacturing companies, this is largely dependent on machine tools and equipment functioning with minimal disruptions to ensure that that what has been planned for production is produced and delivered on time. Malfunctioning equipment and machinery can be an undesirable liability, let alone in chemical and processing industries where the blending of chemicals has to be stringently followed to ensure high quality products, more so in the food industry. Apart from meeting the required specifications and quality of margarine, the oil company needed to ensure that their master churn mixer was properly controlled and monitored to maintain set operating parameters of oil and water ratios and operating temperature at stipulated values otherwise the product quality would be compromised. The performance of the master churn mixer was not only measured internally but also by means of customer satisfaction and meeting their requirements and orders. This performance is generally determined from the overall equipment effectiveness over a period of time and compared with set standards. Most food processing companies in a developing country such as Zimbabwe still employ the traditional means of manual production planning with no means of automation or simulations to predict performance.

Modern means of production planning and scheduling which ideally should include automated control and monitoring of equipment, ensures uninterrupted processing and quality assurance. Most failures in equipment and reduced performance can be traced to causes which may be rooted in the past or feeder departments to the workstation in question. These root causes were traced in this research were noted over a period of six months, under separate life cycle assessments and categories leading to zeroing in on the key parameters of vegetable oil and water ratios as well as the operating temperature. This technique is a business quality system and life cycle management indicator that drives defect removal and the adoption of better asset life cycle practices. These assessments covered such aspects as manufacturing and processing, equipment installation and maintenance, mixing of chemicals, human errors including workmanship, procurement and storage problems.

In this research, sensors and PLCs were employed to control and monitor the operating parameters for the master churn mixer from a manual to an automated system in the production of various types of margarine products. Although the temperature was controlled and maintained at $38^{\circ} \mathrm{C}$, some unexpected interruptions in production after installing the PLCs pointed to the need for further work in resizing of the sensors to ensure consistent and uninterrupted processing. Focus for this research was on monitoring and control of the master churn mixer but this does not operate in isolation. With resources permitting, future and further work is necessary to develop a comprehensive approach combining the fuzzy logic technique proposed and employed in this research, with those of genetic algorithms and neural networks owing to the limitations of fuzzy logic such as approximation. This may provide a 
full proof control and monitoring of all the processes and equipment including adjacent workstations such as the testers, fillers and chillers.

\section{Conclusions}

The production planning and control of the master churn mixer was based on the problems studied at an oil company in Zimbabwe which faced persistent delays in meeting customer orders due to the inconsistent quality of margarine that did not meet required specifications in some of the batches. The research revealed that this was largely due to fluctuations in key operating parameters of the vegetable oil and water ratios as well the operating temperature, prompting the need for a system to control and monitor these parameters. In conjunction with MATLAB, sensors and PLCs were used to develop an intelligent fuzzy logic controller using a Mamdani fuzzy inference approach. The developed controller was capable of controlling, monitoring and maintaining the key parameters at stipulated ratios of $80 \%$ and $20 \%$ for the vegetable oil and water respectively, while the operating temperature was kept at $38^{\circ} \mathrm{C}$, hence the company realized some improvement in throughput. However, due to limitations in the fuzzy logic technique, further work was recommended to extend and combine this technique with that of genetic algorithms and neural networks in handling the control and monitoring of all the equipment at the company including testers, fillers and chillers.

\section{References}

[1] Kumar Sinha, A., Anand, A.: Towards fuzzy preference relationship based on decision making approach to access the performance of suppliers in environmental conscious manufacturing domain, Journal of Computers and Industrial Engineering, Vol. 105, pp. 39-54 (2017)

[2] Sager, B., Hawer, S., Reinhart, G.: A Performance Measurement System for Global Manufacturing Networks, Procedia CIRP, Vol. 57, pp. 61-66 (2016)

[3] Bhanot, N., Venkateswara Rao P., Deshmukh, S.G.: An integrated approach for analyzing the enablers and barriers of sustainable manufacturing, Journal of Cleaner Production, Vol. 142, pp. 4412-4439 (2017)

[4] Kotler, P., Armstrong, G., Brown, L., Adam, S.: Principles of Marketing, 14th Ed., Pearson Prentice Hall, New Jersey (2012)

[5] Anil Kumar, S., Suresh, N.: Operations Management, New Age International Publishers, New Delhi (2009)

[6] Adam, E.E., Ebert, R.J.: Production and Operations Management: Concepts Models and Behavior, Prentice Hall, New Delhi (2003)

[7] Kidanu, E,: Analysis of Butter Supply Chain: the Case of Atsbi-Wenberta and Alamata Woredas, Tigray, Ethiopia, MSc Thesis, Haramaya University, Alemaya (2010)

[8] Zimwara, D., Goriwondo, W.M, Mhlanga, S, Chasara, T, Chuma, T., Gwatidzo, O., Sarema B.: World Class Manufacturing status, Assessment for a Margarine Producing Company in Zimbabwe, International Journal of Innovative Technology and Exploring Engineering, 2(1), Blue Eyes Intelligence Engineering \& Sciences (2012)

[9] Lim, K.S.: How products are made: An illustrated guide to product manufacturing, Gale Publishing, California (1995)

[10] Alexandersen, K. A.: Margarine Processing Plants and Equipment. In: Shahidi, F. (ed.) Bailey's Industrial Oil and Fat Products, 6th Ed., John Wiley \& Sons, New Jersey (2005) 
[11] Ray, K.S., Chakraborty, A.: A fuzzy version of default logic, International Journal of Intelligent Computing and Cybernetics, Vol. 4 Issue 1, pp. 5-24 (2011)

[12] Vidyadhar, R., Sudeep Kumar, R., Vinodh, S., Antony, J.: Application of fuzzy logic for leanness assessment in SMEs: a case study, Journal of Engineering, Design and Technology, Vol. 14 Issue 1, pp. 78-103 (2016)

[13] Yao, J., Ryan, M., Power, J.: Using Fuzzy Logic towards Intelligent Systems, Prentice Hall International, London (1994)

[14] Jantzen, J.: Foundations of Fuzzy Control, Department of Automation. Tech. report no 98-E 868 logic, Technical University of Denmark, Copenhagen (1998).

[15] Noor, S.B.M., Khor, W.C., Ya'acob, M.E.: Fuzzy logic control of a nonlinear pH-neutralization in waste water treatment plant, International Journal of Engineering and Technology, Vol. 1 Issue 2, pp 197-205 (2004)

[16] Geering, H.P.: Introduction to fuzzy Control, 3rd Ed., Swiss Federal Institute of Technology, Zurich (1998)

[17] Simoes, M.G.: Introduction to Fuzzy Control, Journal of the Colorado School of Mines. Colorado (2001)

[18] Muller, M.: Essentials of Inventory Management, 2nd Ed., American Management Association, New York (2011)

[19] Khosravanian, R., Sabah, M., Wood, D.A., Shahryari, A.: Weight on drill bit prediction models: Sugeno-type and Mamdani-type fuzzy inference systems compared, Journal of Natural Gas Science and Engineering, Vol. 36, pp. 280-297 (2016)

[20] Wang, C.: A Study of Membership Functions on Mamdani-Type Fuzzy Inference System for Industrial Decision-Making, MSc Theses, Lehigh University, Pennsylvania (2015) 